\title{
Reserve network planning for fishes in the middle and lower Yangtze River basin by systematic conservation approaches
}

\author{
Xinyi Huang ${ }^{1},{\operatorname{Fan~} \mathrm{Li}^{1} \& \text { Jiakuan Chen }}^{1,2 *}$ \\ ${ }^{1}$ Institute of Biodiversity Science, Fudan University, Shanghai 200438, China; \\ ${ }^{2}$ Center for Watershed Ecology, Institute of Life Science, Nanchang University, Nanchang 330031, China
}

Received May 21, 2015; accepted August 14, 2015; published online January 7, 2016

\begin{abstract}
Although China has established more than 600 wetland nature reserves, conservation gaps still exist for many species, especially for freshwater fishes. Underlying this problem is the fact that top-level planning is missing in the construction of nature reserves. To promote the development of nature reserves for fishes, this study took the middle and lower reaches of the Yangtze River basin (MLYRB) as an example to carry out top-level reserve network planning for fishes using approaches of systematic conservation planning. Typical fish species living in freshwater habitats were defined and considered in the planning. Based on sample data collected from large quantities of literatures, continuous distribution patterns of 142 fishes were obtained with species distribution modeling and subsequent processing, and the distributions of another eleven species were artificially designated. With the distribution pattern of species, Marxan was used to carry out conservation planning. To obtain ideal solutions with representativeness, persistence, and efficiency, parameters were set with careful consideration regarding existing wetland reserves, human disturbances, hydrological connectivity, and representation targets of species. Marxan produced the selection frequency of planning units (PUs) and a best solution. Selection frequency indicates the relative protection importance of a PU. The best solution is a representative of ideal fish reserve networks. Both of the PUs with high selection frequency and those in the best solution have low proportions included in existing wetland nature reserves, suggesting that there are significant conservation gaps for fish species in MLYRB. The best solution could serve as a reference for establishing a fish reserve network in the MLYRB. There is great flexibility for replacing selected PUs in the solution, and such flexibility facilitates the implementation of the solution in reality in case of unexpected obstacles. Further, we suggested adopting a freshwater management framework in the implementation of such solution.
\end{abstract}

middle and lower Yangtze River basin, fish conservation, systematic conservation planning, reserve network, Marxan

Citation: Huang, X., Li, F., and Chen, J. (2016). Reserve network planning for fishes in the middle and lower Yangtze River basin by systematic conservation approaches. Sci China Life Sci 59, 312-324, doi: 10.1007/s11427-015-4950-0

\section{INTRODUCTION}

China has established more than 600 wetland nature reserves, of which the total planned area is over $440,000 \mathrm{~km}^{2}$ and most are freshwater nature reserves (Chen and Huang, 2010). Those nature reserves play important roles in protecting freshwater wetland ecosystem and biodiversity. With the aid of freshwater nature reserves, some endangered

*Corresponding author (email: jkchen@fudan.edu.cn) species are maintained, such as Alligator sinensis and Nipponia Nippon, whose populations are kept from dwindling in nature reserves (Ding and Li, 2006; Wang et al., 2010). Some wetland ecosystems are rehabilitated within wetland nature reserves, such as Honghu Lake wetlands, where the grass coverage increased from $40 \%$ to $80 \%$ through five years of rehabilitation (Wen and $\mathrm{Li}, 2010$ ).

The above achievements could be attributed to protection measures for rescue of endangered wildlife and the rehabilitation of habitats within individual nature reserves. In gen- 
eral, however, freshwater wildlife is still declining due to the continuing disturbance of human activities. Taking the middle and lower reaches of the Yangtze River basin (MLYRB) for example, the numbers of commercial fish populations is significantly decreasing (Cao, 2009; Fu et al., 2003; Yang et al., 2007). Even for those endangered animals that are well protected in nature reserves, such as Alligator sinensis and Neophocaena phocaenoides, their populations in the wild are also declining due to the destruction of their habitat (Shao, 2004; Yang et al., 2007). Underlying this problem is the fact that in the primary stage of constructing nature reserves in China, such nature reserves would focus on protection measures for rescue while omitting top-level planning for the spatial layout of nature reserve networks. Without scientific top-level planning, conservation gaps for many species and ecosystems might exist in whole nature reserve networks (Liu et al., 2003), including wetland (freshwater) nature reserve networks (Huang and Chen, 2012b). Therefore, from the perspective of developing wetland nature reserves, scientifically establishing a freshwater nature reserve network is a step in the right direction.

Furthermore, nature reserves specially established for freshwater fish conservation is not enough. According to a rough estimate, only 30 out of over 600 wetland nature reserves (less than $5 \%$ ) across the country regard freshwater fishes as the main object of protection, which obviously could not meet the protection needs of freshwater fishes as they are the main groups of freshwater taxa. In essence, this also results from the absence of top-level planning for wetland nature reserves. Therefore, establishing fish reserves should be promoted and strengthened in the future, and scientifically building a fish reserve network should certainly be an approach worthy of priority consideration.

Systematic conservation planning (SCP) is an important methodology for designing a regional reserve network (Margules and Sarkar, 2007; Margules and Pressey, 2000), which is aimed at designing a reserve network that meets representativeness and persistence (the former meaning biodiversity as a whole should be represented in the protected area network (Austin and Margules, 1986), and the latter meaning the network should ensure the long-term survival of species and the maintenance of natural processes by excluding threats (Soulé, 1987)). Some scientists put forward another set of objectives backed by the same meaning, namely comprehensiveness, adequacy, and representativeness (CAR) (Linke et al., 2011; Possingham et al., 2006). Efficiency is also highlighted in SCP, which means to minimize the cost of reserve construction on the basis of achieving representativeness and persistence (Kirkpatrick, 1983; Possingham et al., 2006; Sarkar et al., 2006; Vanewright et al., 1991). Currently, different types of software for SCP is developed and widely used, such as Marxan (Game and Grantham, 2008) and C-plan (Pressey et al., 2009), and conservation planning using this methodology has been applied in various parts of the world (Cowling and Pressey, 2003; Rondinini and Pressey, 2007; Smith et al., 2006; Zhang et al., 2010).

The Yangtze River is the third largest river in the world and the largest river in China. The range of the middle and lower reaches starts from Yichang and ends at Shanghai, where the river empties into the East China Sea. The MLYRB consists of plains and hilly surrounding areas, with a total area of about 0.77 million $\mathrm{km}^{2}$. This region is intertwined with a complex freshwater ecosystem, which is characterized by the main stream of the Yangtze River and densely covered tributaries and lakes (Chen and Huang, 2010). Due to rich wetland resources and vast waters, the wetlands in the MLYRB have a high diversity of fishes. However, the survival of such fishes in the MLYRB has been greatly disturbed by humans. Over the course of history, cultivation has reduced living spaces of freshwater fishes. During the past four decades, hydrological changes, such as dam construction across rivers, disconnection between rivers and lakes by sluices, and intensification of point and non-point source pollution, have directly threatened the survival of freshwater fishes in the MLYRB (Chen et al., 1997; Dudgeon, 2010; Huang and Chen, 2010; Yang et al., 2007). Because of the high urgency of fish conservation in MLYRB, we chose this region as an example to carry out fish conservation planning by systematic approaches, as well as to provide reference for future development of fish reserve network in this region.

In this study, MLYRB was divided into 2,321 planning units (PUs) with a mean area of $315 \mathrm{~km}^{2}$ based on practicality. We collected spatial distribution information of fish species through an extensive literature investigation, and gained distribution data of each species through species distribution modeling (SDM) with Maxent (Phillips et al., 2006, 2004) and subsequent processing. In a Marxan analysis, representativeness, persistence, and efficiency were considered by using available input data and setting appropriate parameters. Two results were finally obtained: the selection frequency of each PU in 100 Marxan runs and the best solution of the 100 runs. In addition, such results were visualized and compared to the existing wetland nature reserve network.

\section{RESULTS}

\section{SDM and identification of presence patterns of fish spe- cies}

In total, the occurrence probability patterns of 142 species were successfully predicted by Maxent (Phillips et al., 2006, 2004) (Table S1). Finally, presence patterns of the 142 successful modeled species were adjusted based on the rules described in Methods. Figure 1 shows the occurrence probability patterns predicted by Maxent and the finally acknowledged presence patterns of six of those fish species. 


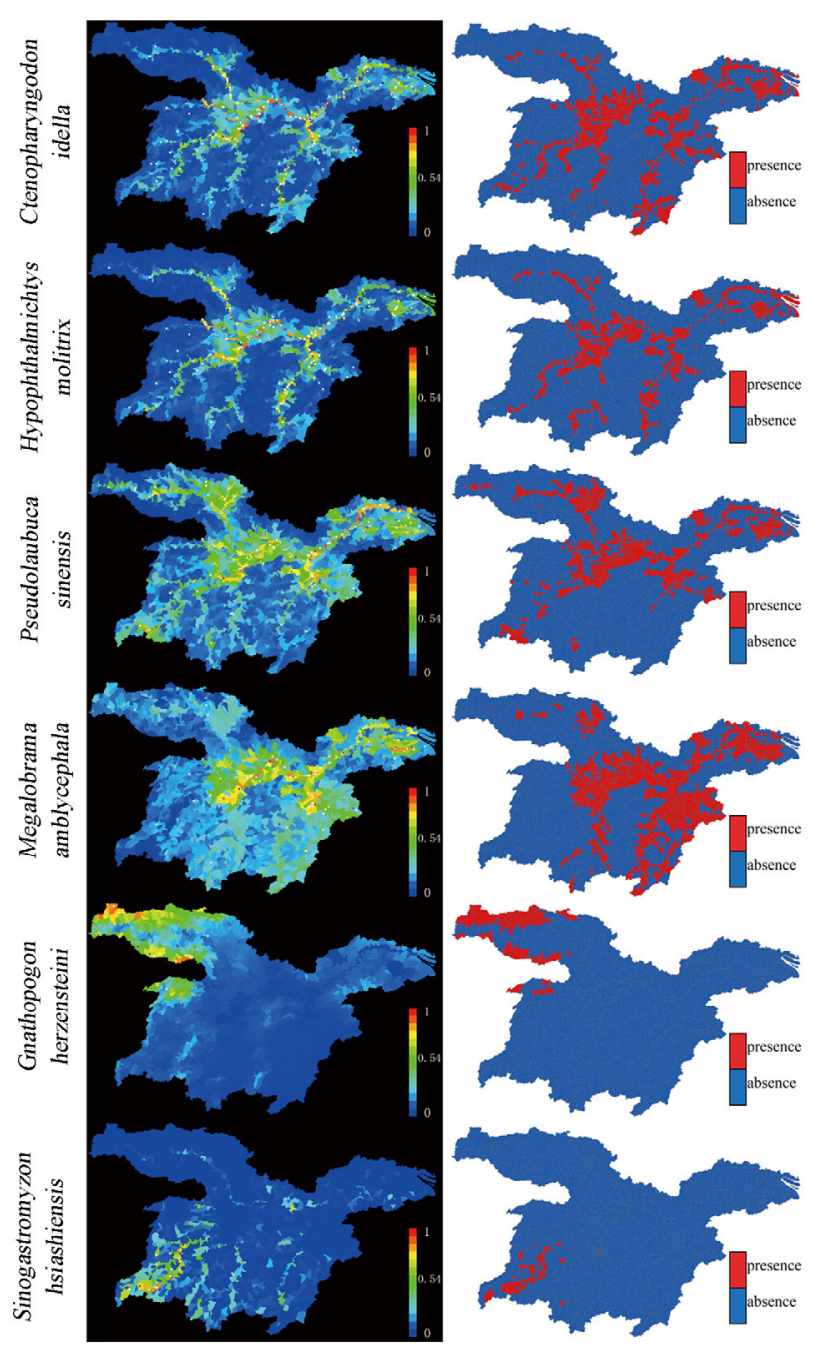

Figure 1 Occurrence probability patterns predicted by SDM (left) and finally accepted presence patterns (right) of six fish species.

\section{Selection frequency}

Marxan was carried out with distribution information of 153 fish species, including 142 fish species whose distributions were predicted by SDM and subsequent processing, and 11 fish species whose distributions were directly designated according to literatures and advice from experts (see Methods). Upon recording the selection frequencies of the 2,321 PUs in the 100 Marxan solutions (Figure 2), 159 PUs were found to have selection frequencies equal to or larger than 80 , comprising only $8.6 \%$ of all the PUs that were selected at least once in the 100 solutions. Of the 159 frequently selected PUs, $49(30.8 \%)$ are PUs of fish reserves artificially locked in the solutions, $23(14.5 \%)$ are PUs of wetland nature reserves for other objects, and the remaining 87 $(54.7 \%)$ PUs are out of the existing wetland nature reserve network.

\section{Best solution}

The 549 PUs designated in the best solution are widely dis- tributed in the whole MLYRB, comprising $23.7 \%$ of all the PUs (Figure 3). Among the 549 PUs, 49 (8.9\%) are PUs of existing fish reserves, $70(12.8 \%)$ are PUs of wetland nature reserves for other protection objects, and 430 (78.3\%) are PUs not turned into wetland nature reserves.

\section{DISCUSSION}

\section{Conservation gaps for fish species in existing wetland nature reserve network}

We obtained the distribution selection frequency of PUs and the best solution. From the two aspects, the conservation gaps for fish species are obvious.

Selection frequency is considered as "irreplaceability" for a PU (Game and Grantham, 2008), indicating the unlikelihood of a PU being replaced in different solutions. Thus, an area with a high selection frequency is, to some extent, an important area for protection. In our study, up to $54.7 \%$ of the frequently selected PUs (selection frequen$c y \geqslant 80$ ) are not included in the existing wetland nature reserve network. Though an efficient reserve network does not necessarily include all of those important areas, the fact that more than half of the important areas for fish protection are not protected reflects the significant conservation gaps for fish species.

The best solution is a typical representative of fish reserve networks with representativeness, persistence, and efficiency in the MLYRB. With reference to the best solution, PUs of existing fish reserves constitute only $8.9 \%$ of all the PUs in the solution, indicating that there are obvious gaps for establishing a fish reserve network. The PUs of wetland nature reserves for other protection objects account for $12.8 \%$, indicating that they will be able to play a role in the fish reserve network if the function of fish conservation is added to them. However, a high proportion (78.3\%) of the PUs is not of wetland nature reserves. This indicates that a considerable number of additional reserves should be established to constitute a scientific fish reserve network.

These conservation gaps of fishes in turn reflect the importance of carrying out fish reserve network planning in MLYRB.

\section{Solution flexibility}

Marxan aims to find an optimal solution by minimizing an objective function (see Methods), so all 100 solutions obtained had small objective function values, and the best solution is the one with the minimum value. Among the 100 solutions only a small number $(8.6 \%)$ of PUs are highly preferred (frequency $\geqslant 80$ ), including those PUs artificially locked in solutions when running Marxan (existing fish nature reserves). This suggests that most of the PUs selected in the 100 runs have a relatively low selection frequency. In addition, to some extent, it indicates that when generating a solution with a small value of the Marxan objective func- 


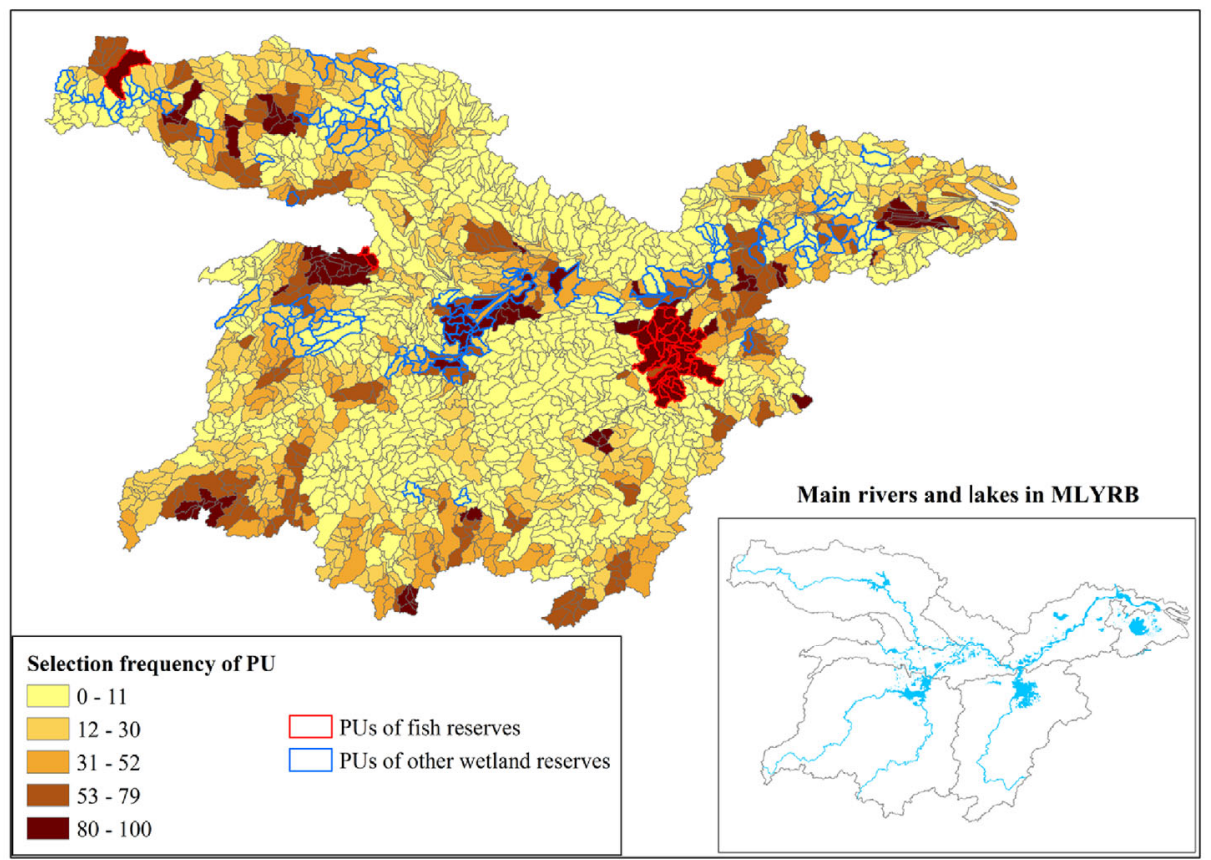

Figure 2 The pattern of selection frequencies of all the PUs in 100 Marxan solutions and the distribution of existing wetland nature reserves.

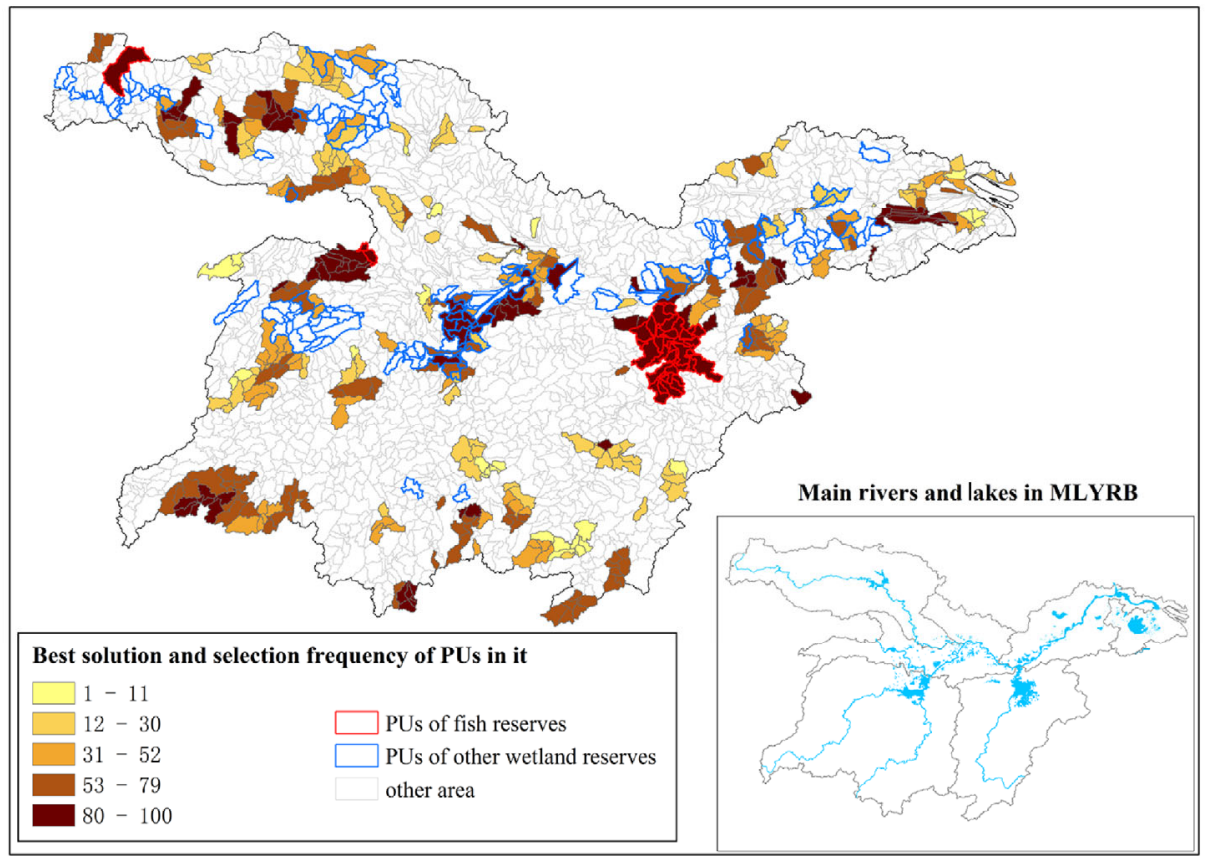

Figure 3 Selected PUs of the best solution of 100 Marxan runs and the distribution of existing wetland nature reserves.

tion, there is great flexibility for replacing the selected PUs, and such solution flexibility facilitates its implementation in reality in case of unexpected obstacles. Assuming the best solution was applied at the beginning, once some of the designated PUs are required for other usage, we could choose other PUs instead without a significant increment of cost or segmentation of the whole reserve network.

The best solution is the optimal choice based on the cur- rent data and calculation, though it might be adjusted due to unforeseen circumstances. We suggest establishing a fish reserve network in the MLYRB on the basis of the best solution first. With growing information in the future, the applied solution could be re-examined and re-adjusted. We suggest that reserve construction in PUs with high selection frequency should take precedence. The reason is that they are not likely to be replaced if the applied solution should 
be adjusted halfway.

\section{A feasible management framework}

Considering the implementation of the solution, there are two problems that arise: (i) from a regional-scale perspective, the PUs designated in the best solution account for $23.7 \%$ of all the PUs, suggesting that the area proportion of the suggested fish reserve network in the MLYRB probably exceeds that of all nature reserves national wide (15\%) (http://sts.mep.gov.cn); (ii) from a local-scale perspective, the ranges of reserves based on PUs include not only fresh waters but also terrestrial areas, and the scale of a single PU or cluster of PUs is larger than that of a regular wetland nature reserve (the average area of a PU in our study is $315 \mathrm{~km}^{2}$ while that of a wetland nature reserve in MLYRB is $158 \mathrm{~km}^{2}$ ). Consequently, it is unrealistic to set all the suggested PUs or PU clusters as strict nature reserves.

Thus, we suggest adopting the freshwater management framework of Abell et al. (2007) with some modification in the implementation of the reserve network. First, an individual PU or a cluster of PUs included in our reserve network were seen as a catchment management zone, within which catchment-scaled management approaches would be applied, such as maintaining riparian buffers of appropriate widths along all streams and restricting the use of pesticides and fertilizers. Such catchment management zones would be seen as non-strict protected areas, in which a certain degree of human activity is allowed. Second, within catchment management zones, freshwater focal areas, which cover important freshwater habitats for fish species to spawn, grow, or forage, should be further identified. Strict nature reserves should be located in such "freshwater focal areas" where human activities are strictly forbidden. Third, critical management zones should be identified, which is essential to maintain the function of freshwater focal areas. For instance, a critical management zone could be a river which serves as a migration corridor for fishes from one freshwater focal area to another. Such areas could be appointed as strict or non-strict reserves depending on specific conditions.

At present, the development of nature reserves in China is at a conjuncture from number increase to quality improvement. Considering quality improvement, strengthening management of each nature reserve to enhance effectiveness is the main way from the perspective of local effort, and scientifically establishing the nature reserve network is the key of regional or national effort. With regard to freshwater conservation, there are pressing needs to fill the conservation gaps of fishes by readjusting the structure of the fish reserve network. Thus, though there might be some uncertainties and limitations, our reserve network planning provides a reference for future development of fish reserves in MLYRB. Currently, regional conservation planning using SCP approaches is just unfolding in China (Zhang et al., 2015). Since the series of methods applied in our study (de- scribed below) are feasible and practical under the conditions in China, they could provide valuable references in future studies of reserve network planning in China.

\section{METHODS}

\section{Fishes sample data}

The list of fishes in the MLYRB was summarized based on more than 100 journal articles (nearly all) on the themes of "fish diversity", "species composition of fish community", or "fishery resources", which were extracted from the China National Knowledge Infrastructure (CNKI) by late 2013 and scientific investigation reports of some nature reserves within the region. The study by Fu et al. (2003) served as an important reference to cross-reference the list. The taxonomy of fishes was verified according to FishBase (www. fishbase.org), Fauna Sinica (Chen Y.Y. et al., 1998; Chu et al., 1999; Yue P.Q. et al., 2000; Zhang, 2001), and the latest literatures on the theme of fish taxonomy. In total, 335 species (or subspecies) were recorded in the above sources. Based on the distribution range, habitat requirements and lifecycles, typical fish species living in freshwater habitats of MLYRB were defined as follows: (i) freshwater fishes endemic to the MLYRB; and (ii) freshwater fishes or migratory fishes that have the MLYRB serving as an important part of their distribution range. These fishes were screened out for use in later planning. Estuarine fishes, exotic fishes, fishes that were distributed but now are extinct in the MLYRB, and fishes with the MLYRB only bordering the edge of their distribution range were excluded. In total, 190 species were selected for our planning at the beginning.

Sample data of the 190 species were collected from the following three sources: (i) more than 100 journal articles and scientific investigation reports of the nature reserves mentioned above; (ii) literatures providing the sample locations of fish species collected by searching CNKI with the name of each fish species; and (iii) Fauna Sinica (Chen Y.Y. et al., 1998; Chu et al., 1999; Yue P.Q. et al., 2000; Zhang, 2001) and regional ichthyofauna (East China Sea Fisheries Research Institute of Chinese Academy of Fishery Sciences, 1990; Hunan Fisheries Science Institute, 1980; Laboratory of fish of Hubei Hydrobiology Institute, 1976; Mao and Xu, 1991; Ni and Wu, 2006; Yang, 1988). Sample locations were digitalized in ArcGIS 10.1 (ESRI, 2012). Among the 190 species, continuous distribution patterns of 179 species were to be created through species distribution modeling (SDM) and subsequent processing. The remaining 11 were narrow-distributed species or species with clear distribution ranges, whose presence sites were designated according to descriptions in literature and advice from experts.

\section{Hydrological framework}

According to Linke et al. (2008) and Heiner et al. (2011), 
the freshwater network and the watershed hierarchy were created from the STRM-90 Digital Elevation Model (DEM, http://srtm.csi.cgiar.org) using ArcHydro 10.1 (Maidment, 2002) built in ArcGIS 10.1 (ESRI, 2012). To create a framework with a fine resolution that remains coarse enough to fit fish sample data, the freshwater network was delineated by streams with catchment areas larger than 200 $\mathrm{km}^{2}$. Every sub-catchment associated with a stream segment under the framework was used as a planning unit (PU). The following hierarchy pattern was delineated according to the framework developed by Higgins et al. (2005). Tier I: zoogeographic unit, including the whole MLYRB. Tier II: ecological drainage units (EDUs) were defined as traditionally designated sub-watersheds of the Yangtze River basin nested within the Zoogeographic Unit (Changjiang Hydrological Committee of Hydrology Ministry, 1999) (Figure 4), namely, the Han River basin, the Dongting Lake basin, the Poyang Lake basin, the Tai Lake basin, the basin of the middle Yangtze River mainstream, and the basin of the lower Yangtze River mainstream. Tier III: aquatic ecosystems (AEs) were even smaller units nested within the EDUs. AEs were defined as sub-catchments of the stream segments, and each AE is a PU (Figure 4). In total, 2,321 PUs were created with a mean area of $315 \mathrm{~km}^{2}$.

We did not use stream segments as PUs, for not all sample sites of fishes obtained from existing historical literature were located right on the streams (drainage lines) that we created.

\section{SDM and identification of presence patterns of fish spe- cies}

SDMs were used to create a continuous distribution pattern of fish species. According to Esselman and Allan (2011), SDMs were carried out with Maxent (Phillips et al., 2006, 2004). Maxent requires only species presence-only data and performs well with small sample sizes (Phillips et al., 2006, 2004). According to some studies on fishes (Esselman and Allan, 2011; Hermoso et al., 2011b; Moilanen et al., 2008), a series of independent variables were chosen, and their values were homogenized within each PU (Table 1). Then, values of all the variables were standardized across the planning region. According to Esselman and Allan (2011) and Linke et al. (2008), overfitting was reduced by two methods. First, species with less than 10 sample sites in our database (Table S1) were removed. Second, a principal component analysis (PCA) was carried out to reduce the number of variables from 21 to seven (Table 2).

We adopted the default parameters of Maxent (Phillips et al., 2006) and the following customized settings: application of random seed and $20 \%$ of the localities used as test data. Modeling of a species was seen as successful if both of its training and test area under receiver-operating characteristic curve (AUC) value were equal to or above 0.75 . Otherwise, it would be a failure and the corresponding species would be removed in the following steps (Table S1). The outputs of Maxent were maps of continuous probability (from zero to one) of species occurrence.

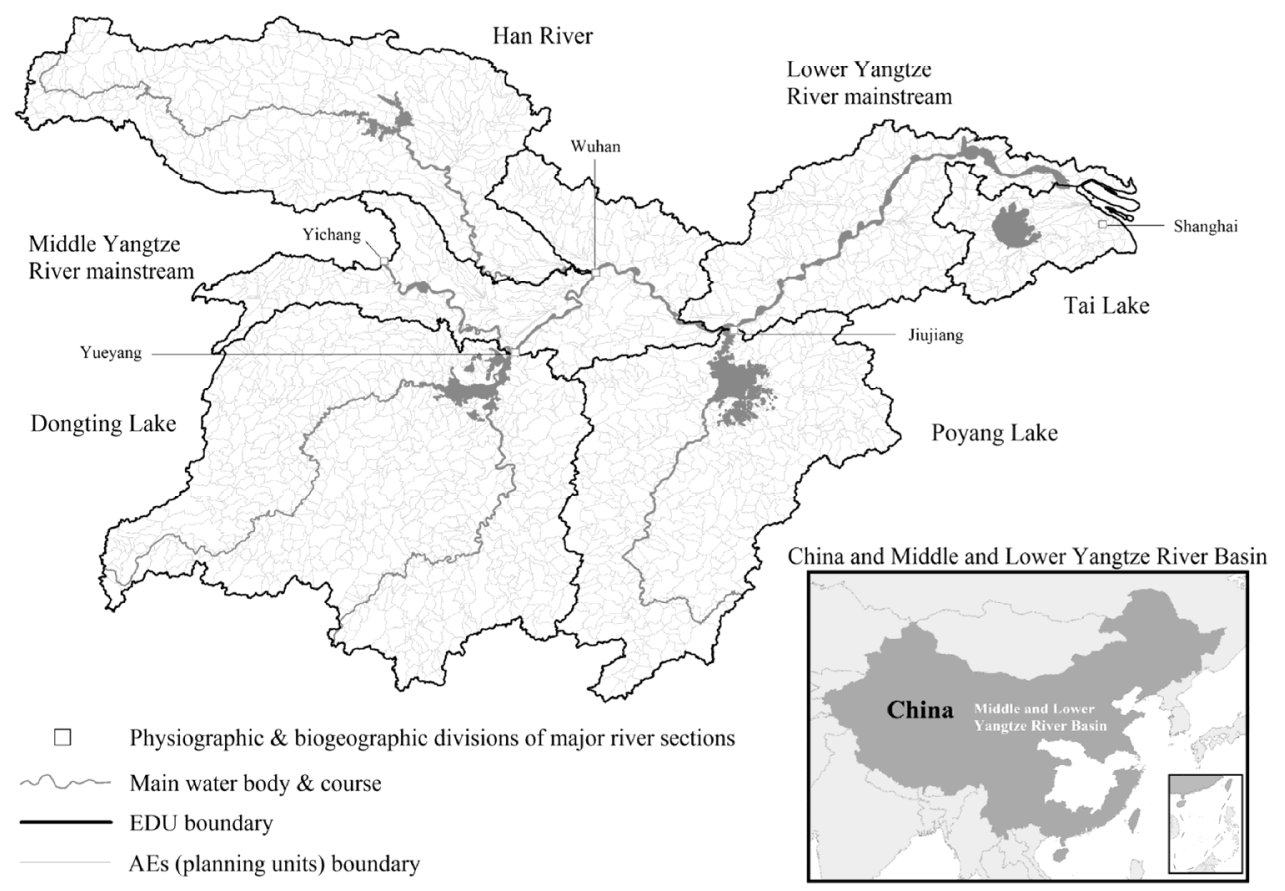

Figure 4 Hydrological framework of the planning. The middle and lower reaches of the Yangtze River basin is defined as a single Zoogeographic Unit and is divided into six Ecological Drainage Units (EDUs). Aquatic Ecosystems (AEs) are nested within EDUs and each AE is used as a PU in the present study. 
Table 1 Environmental variables prepared for fish species distribution modeling in Maxent

\begin{tabular}{|c|c|c|c|c|}
\hline Variable (units) & Min & Max & Mean & Source of original data \\
\hline \multicolumn{5}{|l|}{ Sub-catchment climate } \\
\hline Annual mean (air) temperature $\left({ }^{\circ} \mathrm{C}\right)$ & 8.2 & 19.9 & 15.9 & Bioclim (Hijmans et al., 2005) \\
\hline Annual precipitation (mm) & 723.5 & 1994.1 & 1298.1 & Bioclim (Hijmans et al., 2005) \\
\hline Max temperature of warmest month $\left({ }^{\circ} \mathrm{C}\right)$ & 23.2 & 34.7 & 31.5 & Bioclim (Hijmans et al., 2005) \\
\hline Min temperature of coldest month $\left({ }^{\circ} \mathrm{C}\right)$ & -8.4 & 5.1 & 0.1 & Bioclim (Hijmans et al., 2005) \\
\hline Precipitation of wettest month (mm) & 117.3 & 340.9 & 214.6 & Bioclim (Hijmans et al., 2005) \\
\hline \multicolumn{5}{|l|}{ Sub-catchment geography } \\
\hline Average catchment elevation (m) & 0.57 & 1856.2 & 383.2 & SRTM 90m (http://srtm.csi.cgiar.org) \\
\hline Average catchment slope $(\%)$ & 0 & 56.2 & 17.6 & SRTM 90m (http://srtm.csi.cgiar.org) \\
\hline \multicolumn{5}{|l|}{ Sub-catchment hydrological properties } \\
\hline Flow accumulation (pixels) & 887 & 228142440 & 3975865 & SRTM 90m(http://srtm.csi.cgiar.org) \\
\hline Total surface area of lakes which overlap the PU $\left(\mathrm{km}^{2}\right)$ & 0 & 2432 & 57 & Lake Database in China (Jiang, 2002) $\left.{ }^{a}\right)$ \\
\hline Hydro distance to nearest lake $(\mathrm{km})$ & 0 & No river connected ${ }^{\text {b) }}$ & - & $\begin{array}{l}\text { Lake Database in China (Jiang, 2002) } \\
\text { SRTM 90m (http://srtm.csi.cgiar.org) }\end{array}$ \\
\hline Upstream distance to furthest basin divide $(\mathrm{km})$ & 0 & 2550 & 156 & SRTM 90m (http://srtm.csi.cgiar.org) \\
\hline Distance downstream to sea $(\mathrm{km})$ & 0 & 2488 & 1388 & SRTM 90m (http://srtm.csi.cgiar.org) \\
\hline \multicolumn{5}{|l|}{ Sub-catchment soil proportions $(\%)$} \\
\hline Aliols & 0 & 100 & 8.3 & $\begin{array}{l}\text { Harmonized world soil database } \\
\text { (FAO/IIASA/ISRIC/ISSCAS/JRC, 2009) }^{\text {a) }}\end{array}$ \\
\hline Acrisols & 0 & 100 & 28.6 & $\begin{array}{l}\text { Harmonized world soil database } \\
\text { (FAO/IIASA/ISRIC/ISSCAS/JRC, 2009) }^{\text {a) }}\end{array}$ \\
\hline Luvisols & 0 & 100 & 15.6 & $\begin{array}{l}\text { Harmonized world soil database } \\
\text { (FAO/IIASA/ISRIC/ISSCAS/JRC, 2009) }^{\text {a) }}\end{array}$ \\
\hline Cambisols & 0 & 100 & 9.4 & $\begin{array}{l}\text { Harmonized world soil database } \\
\text { (FAO/IIASA/ISRIC/ISSCAS/JRC, 2009) }^{\text {a) }}\end{array}$ \\
\hline Anthrosols & 0 & 100 & 24.3 & $\begin{array}{l}\text { Harmonized world soil database } \\
\text { (FAO/IIASA/ISRIC/ISSCAS/JRC, 2009) }^{\text {a) }}\end{array}$ \\
\hline \multicolumn{5}{|l|}{ Sub-catchment geology coverage $(\%)$} \\
\hline Carbonate rock & 0 & 100 & 40.7 & $\begin{array}{l}\text { Geological Map of China (Scale 1:1,000,000) } \\
\text { (http://gsd.cgs.cn/categories.asp?tp=250W) }\end{array}$ \\
\hline Sub-catchment forest coverage $(\%)$ & 0 & 74.3 & 13.2 & WESTDC_Land_Cover (Ran et al., 2010) ${ }^{\text {a) }}$ \\
\hline
\end{tabular}

a) These datasets were provided by the Environmental and Ecological Science Data Center for West China, National Natural Science Foundation of China (http://westdc.westgis.ac.cn). b) Some sub-catchments are located in estuarine areas, and the hydrological paths between those sub-catchments and lakes flow through salty or brackish waters. Since most fish species in this study are freshwater species and could not migrate from those sub-catchments to lakes through salty or brackish waters, we assumed that those sub-catchments are not connected with lakes. In the calculation, a high value of the parameter "hydro distance to nearest lake (km)" (about 1.5 times of the maximum value for other sub-catchments) was set for those sub-catchments.

Table 2 Variables with high loadings on principal axes ${ }^{\text {a) }}$

\begin{tabular}{|c|c|c|c|c|c|c|}
\hline $\mathrm{PC} 1$ & PC2 & PC3 & PC4 & PC5 & PC6 & PC7 \\
\hline $\begin{array}{l}\text { Annual mean air } \\
\text { temperature } \\
(0.33544)\end{array}$ & $\begin{array}{l}\text { Annual precipitation } \\
(0.37218)\end{array}$ & $\begin{array}{l}\text { Flow accumula- } \\
\text { tion } \\
(0.69401)\end{array}$ & $\begin{array}{l}\text { Proportion of aliols } \\
(0.56314)\end{array}$ & $\begin{array}{l}\text { Total surface area of } \\
\text { lakes overlapping with } \\
\text { the PU } \\
(0.52481)\end{array}$ & $\begin{array}{l}\text { Sedimentary clastic } \\
\text { rock coverage } \\
(0.65464)\end{array}$ & $\begin{array}{l}\text { Total surface area of } \\
\text { lakes overlapping } \\
\text { with the PU } \\
(0.76016)\end{array}$ \\
\hline $\begin{array}{l}\text { Max temperature of } \\
\text { warmest month } \\
(0.33541)\end{array}$ & $\begin{array}{l}\text { Precipitation of } \\
\text { wettest month } \\
(0.36028)\end{array}$ & $\begin{array}{l}\text { Upstream distance } \\
\text { to furthest basin } \\
\text { divide } \\
(0.68133)\end{array}$ & $\begin{array}{l}\text { Sedimentary castic } \\
\text { rock coverage } \\
(0.37282)\end{array}$ & $\begin{array}{l}\text { Proportion of } \\
\text { cambisols } \\
(0.41475)\end{array}$ & $\begin{array}{l}\text { Carbonate rock } \\
\text { coverage } \\
(0.40463)\end{array}$ & $\begin{array}{l}\text { Proportion of } \\
\text { cambisols } \\
(0.36552)\end{array}$ \\
\hline $\begin{array}{l}\text { Average catchment } \\
\text { elevation } \\
(0.32435)\end{array}$ & $\begin{array}{l}\text { Proportion of } \\
\text { acrisols } \\
(0.35742) \\
\end{array}$ & $\begin{array}{l}\text { Proportion of } \\
\text { anthrosols } \\
(0.1188)\end{array}$ & $\begin{array}{l}\text { Catchment forest } \\
\text { coverage } \\
(0.3318)\end{array}$ & $\begin{array}{l}\text { Proportion of aliols } \\
(0.37085)\end{array}$ & $\begin{array}{l}\text { Proportion of aliols } \\
(0.37851)\end{array}$ & $\begin{array}{l}\text { Proportion of } \\
\text { luvisols } \\
(0.25018)\end{array}$ \\
\hline
\end{tabular}

a) Variables that were used for modeling are identified in bold. Loadings on PC axes are given in brackets. b) Since the variable "total surface area of lakes overlapping with the PU" had been selected based on PC5, the variable "proportion of cambisols", which had the second highest loadings on PC7, was selected here.

The occurrence probability would be converted into a binary pattern representing the presence/absence of the species. To make sure the PUs that were appointed as spe- cies-present PUs could have a higher probability of species occurrence, the presence/absence threshold was set as follows: for each species, $80 \%$ of its training points with the 
highest probability of species occurrence were selected; next, the minimum probability value of these training points was used as the threshold. Then, PUs with an occurrence probability higher than the threshold were appointed as the potential distribution units (PDUs) of the species.

SDMs identified PDUs of species according to ecological factors in our study. However, as the distribution ranges of many species might cover only part of the MLYRB, namely certain PDUs of some species predicted by SDMs might be located outside their actual distribution ranges, such false-positive presence PUs should be removed.

The delineation of a hydrological framework provided a framework to delineate the distribution range of fishes in the MLYRB. We made an assumption that for each fish species, all its individuals could swim among all its habitats in the basin through watercourses (Bennett, 1998), thus maintaining its current distribution pattern. Therefore, the distribution range of a species should cover all the paths through which its population migrates among all of its habitats. Since the sample sites collected reflect our best knowledge of the occurrence locations of each species, the species' distribution ranges were delineated as follows: for any species, the confluence of all streams running through one or more PUs containing its sample sites was determined. The whole catchment of the said confluence constituted the smallest watershed that covered all the paths through which its individuals migrate among all the sample sites. Therefore, the whole catchment of the confluence was defined as the potential distribution watershed (PDW) of that species (Figure 5A). In addition, we noticed that for some fish species, the PDW's range was large and covered many EDUs, but the sample sites and the distribution ranges described in literatures were only concentrated in several of these EDUs. Consequently, we further defined that only an EDU containing at least one sample site of a species could be seen as its potential distribution EDU (hereinafter referred to as "PDEDU") (Figure 5B). Thus, for the PDUs of a species predicted by SDM, only those located within the overlap between its PDW and PDEDUs were seen as species-present PUs. Then, the adjusted presence patterns of all species were used in a Marxan analysis.

\section{Marxan conservation planning}

Marxan (Ball et al., 2009; Game and Grantham, 2008) was used to carry out reserve network planning. Given the distribution data and representation targets of conservation features (e.g. species), Marxan aims to find an optimal solution (a reserve network) by minimizing an objective function on the basis that representation targets are met (Equation 1). The objective function equals the sum of "conservation feature penalties", "boundary length penalties", and "cost":

$$
\sum \text { Cost }+ \text { BLM } \sum \text { Boundary }+\sum \text { CFPF } \times \text { Penalty, }
$$

where $\sum$ Cost means the total cost of selected PUs in the solution. BLM $\sum$ Boundary means the total boundary length penalties, which represents the total boundary length of the solution. The boundary length modifier (BLM) adds weighted importance relative to the other components of the objective. And $\sum \mathrm{CFPF} \times$ Penalty means the total conservation feature penalties, which are the penalties for not adequately representing conservation features (representation targets are not met). The conservation feature penalty factor (CFPF) adds weighted importance relative to the other components of the objective.

In seeking a minimum objective function, Marxan promotes the minimization of the above three components. The minimization of total cost reflects efficiency, the minimization of total conservation feature penalties insures the adequate representation of conservation features (which reflects representativeness and persistence), and the minimization of total boundary length penalties reduces the fragmentation of the reserve network (which reflects persistence).

In our study, the run mode of Marxan was set as simulated annealing followed by iterative improvement. In the simulated annealing algorithm, the number of iterations was set as $1,000,000$, and the number of temperature decreases was 10,000 for each run (default settings). Considering the objectives of representativeness, persistence, and efficiency, input data and parameters were set as follows.

(i) Conservation features and representation target. Species with successful SDMs and species with presence sites ("presence PUs") designated were used in our SCP. We set representation targets for each species in each EDU separately. Different representation targets were set for fish species according to their protection urgency and endemism. Protection urgency of a species was quantified with the urgency index $(U I)$

$$
U I=\frac{\text { average } D I}{\text { number of presence PUs }} \times \text { Endemism Index, }
$$

where $D I$ means the disturbance index of a PU (see below and Table 3 for further details and calculation of $D I$ ), average $D I$ means the average $D I$ of presence PUs of the species. When the species was endemic to the MLYLB, the Endemism Index was two, otherwise it was one.

According to our calculation, a larger $U I$ of a species indicate its greater demand for protection. With the UIs of all the species calculated, $20 \%$ of the species with the largest $U I$ values were listed as key protection objects and assigned with a representation target of $30 \%$, which means $30 \%$ of their presence PUs in each EDU should be involved in the solution. Besides key protection objects, all the endemic species of the MLYRB were also assigned with a representation target of $30 \%$ since endemic species were of higher conservation value. Then, all the remaining species were assigned with a target of $20 \%$. As treated separately during target setting, the same fish species in different EDUs were regarded as independent conservation features. 

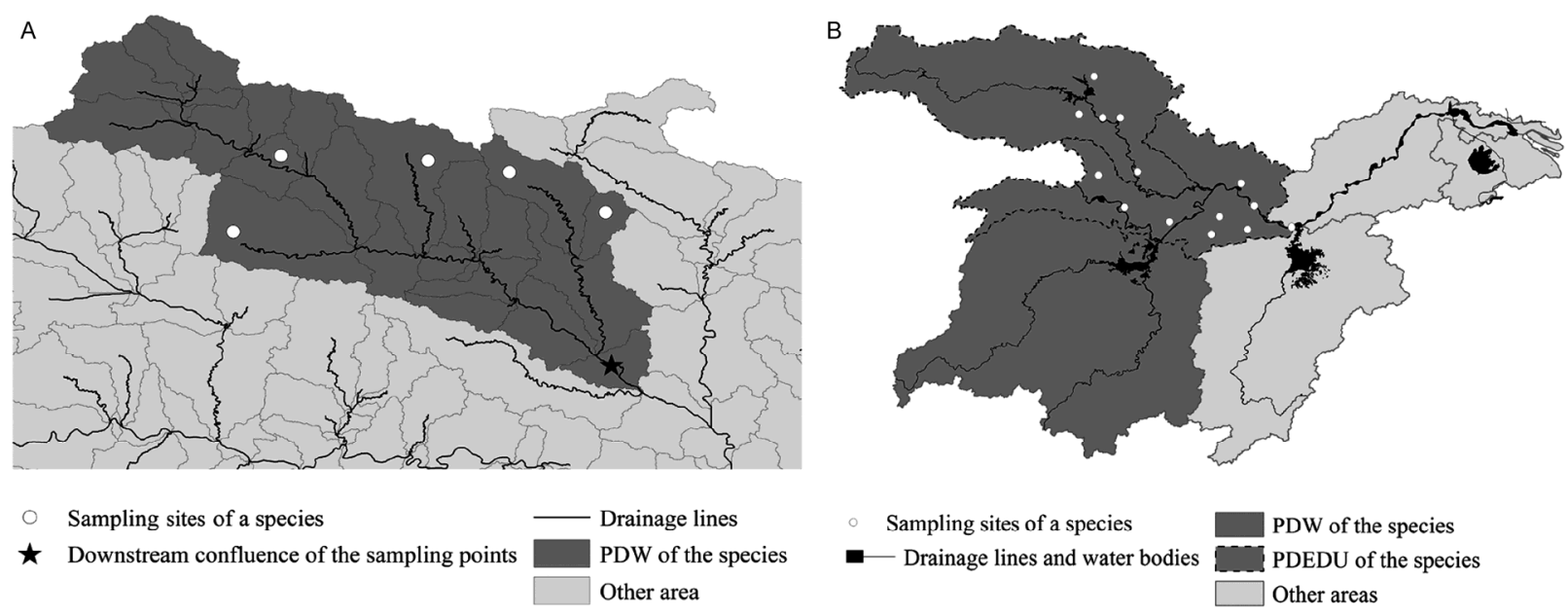

Figure 5 Examples of identifying potential distribution watershed and potential distribution EDUs of fishes in this study. A, Identifying potential distribution watershed of a species. The symbol " $\star$ " represents the confluence of all streams running through one or more PUs containing its sample sites. The whole catchment of the confluence is then designated as the potential distribution watershed (PDW) of the species. B, Identifying potential distribution EDUs (PDEDUs) of a species. Only an EDU containing at least a sample site of the species could be seen as its PDEDU.

Table 3 Disturbance variables used to calculate the disturbance index of each planning unit (PU)

\begin{tabular}{|c|c|c|c|c|}
\hline $\begin{array}{l}\text { Disturbance } \\
\text { type }\end{array}$ & Factor & Variable & $\begin{array}{l}\text { Weight } \\
\text { coefficients }\end{array}$ & Data source \\
\hline \multirow[t]{3}{*}{$\begin{array}{l}\text { Hydrological } \\
\text { change }\end{array}$} & Dam & $\begin{array}{l}\text { Dam density (dam count/PU } \\
\text { area) }\end{array}$ & 15 & Global Reservoir and Dam Database (Lehner et al., 2011) \\
\hline & Sluice & $\begin{array}{l}\text { Sluice density (sluice count/PU } \\
\text { area) }\end{array}$ & 10 & $\begin{array}{l}\text { Code for China Water Gate Name (Ministry of Water } \\
\text { Resource of the People's Republic of China, 2001) }\end{array}$ \\
\hline & Reservoir & $\begin{array}{l}\text { Reservoir impact index (total } \\
\text { capacity of reservoirs/drainage } \\
\text { line length) }\end{array}$ & 5 & Global Reservoir and Dam Database (Lehner et al., 2011) \\
\hline \multirow{2}{*}{$\begin{array}{l}\text { Water pollu- } \\
\text { tion }\end{array}$} & $\begin{array}{l}\text { Chemical plant (a surrogate } \\
\text { of point source pollution) }\end{array}$ & $\begin{array}{l}\text { Chemical plant density (Chem- } \\
\text { ical plant count/PU area) }\end{array}$ & 5 & $\begin{array}{l}\text { Directory of Petroleum and Chemical Business in China } \\
\text { (http://www.chinacyyj.com) }\end{array}$ \\
\hline & $\begin{array}{l}\text { Cropland (a surrogate of } \\
\text { non-point source pollution) }\end{array}$ & Area proportion of cropland & 5 & WESTDC_Land_Cover (Ran et al., 2010) \\
\hline \multirow{2}{*}{$\begin{array}{l}\text { Human de- } \\
\text { velopment } \\
\text { pressure }\end{array}$} & Population pressure & Population density & 5 & $\begin{array}{l}\text { Gridded population of the world v3 } \\
\text { (http://sedac.ciesin.columbia.edu/data/collection/gpw-v3) }\end{array}$ \\
\hline & Urban construction & Area proportion of urban area & 1 & WESTDC_Land_Cover (Ran et al., 2010) \\
\hline $\begin{array}{l}\text { Protection } \\
\text { status }\end{array}$ & $\begin{array}{l}\text { National and provincial } \\
\text { wetland nature reserves as } \\
\text { well as national terrestrial } \\
\text { nature reserves }\end{array}$ & $\begin{array}{l}\text { Area proportion of nature } \\
\text { reserves }\end{array}$ & - & Various sources $^{\text {b) }}$ \\
\hline
\end{tabular}

a) A national list of refiners obtained from an unpublished document. b) A directory of nature reserves was summarized from the "List of Nature Reserves of China (2012)" (http://sts.mep.gov.cn). Geological heritage were excluded. Original drafts of these reserves were collected from reserve institutions, government websites, literatures, public documents of governments, and the World Database on Protected Areas (http://www.unep-wcmc.org/wdpa). All drafts of reserves were digitalized in ArcGIS 10.1 (ESRI, 2012).

(ii) Existing nature reserves. We considered only national and provincial freshwater nature reserves here. The list of freshwater protected areas was summarized from the "List of Nature Reserves of China (2012)" (http://sts.mep. gov.cn). The original drafts of those reserves were collected from institutions of reserves, government websites, literatures, public documents of governments, and the World Database on Protected Areas (http://www.unep-wcmc.org/ wdpa). All the drafts of the reserves were digitalized in ArcGIS 10.1(ESRI, 2012). Due to the presence of eight national and provincial wetland nature reserves (including two fish reserves) in Poyang Lake, some overlapping occurred as described in government documents, and given that the drafts of most of them were unavailable, we regarded the whole lake as an existing wetland and fish reserve. Since the boundaries of wetland nature reserves were not consistent with those of PUs, we designated "PUs of nature reserves" according to the overlap between reserves and PUs. In Marxan, those PUs of freshwater nature reserves for non-fish wildlife or ecosystem were included in the initial reserve system, regardless of whether they took part in the final solution; and those PUs of fish reserves were locked in 
the initial reserve system and could not be removed.

(iii) Conservation feature penalties. The CFPF of all conservation features was set to a high value (100), so that the targets of all conservation features could be met in every scenario.

(iv) Cost of PUs. DI was used to represent cost in Marxan, so that PUs with fewer human disturbances would be preferred in site selection. According to the main sources of human disturbance on freshwater, the DI of each PU was calculated based on nine variables of disturbances, including hydrological changes, water pollution, and human development pressures (Table 3). Values of the variables were standardized (rescaled to values from zero to one). Initial DI of a PU equals to the sum of all standardized variables multiplied by their weight coefficients, which roughly quantified our estimates of the relative influence of each variable on ecological conditions. Since reserves can protect environmental processes needed to sustain freshwater ecosystems, we included the reserve status as a positive attribute in the calculation of the final accepted $D I$

Final accepted $D I$

$=$ Initial $D I \times(1-0.5 \times$ Proportion of nature reserve areas $)$.

(v) Connectivity penalties. Connectivity between PUs through hydrological pathways (longitudinal connectivity) was taken into account by modifying the "boundary length penalty" to the "connectivity penalty" in Marxan in accordance with Hermoso et al. (Hermoso et al., 2012, 2011b). Under this penalty rule, a penalty applies when the upstream or downstream connections of selected PUs were not included in the solution. This approach avoided the selection of isolated PUs and forced the inclusion of hydrologically closer PUs. For each selected PU, when closer upstream or downstream PUs were excluded from the solution, it would lead to a higher penalty (Penalty $=1 /$ distance in $\mathrm{km}$ ) as opposed to when distant PUs were excluded. Considering the attenuation effects, for each PU, only the penalties of excluding the 10 nearest downstream PUs and the 10 nearest PUs in each upstream route were considered to reduce the amount of calculation. The emphasis placed on connectivity was adjusted using a connectivity penalty factor (CPF).

By this time, all data were inputted and all parameters were set, except for the connectivity penalty factor (CPF). To find an appropriate CPF that balanced the weight of the total connectivity penalty with that of the total cost of a solution, the following sensitivity analysis was carried out: Marxan was run in 10 scenarios with different CPFs $(0$, $0.01,0.025,0.05,0.1,0.25,0.5,1,2.5$, and 5) respectively, each for 100 runs. The mean total connectivity penalty and the mean total cost of solutions of these scenarios were compared. As the CPF increases, a decrease in the ratio of the total connectivity penalty to the total cost of PU could be found. When the CPF equals 0.25 , both the total connec- tivity penalty and the total cost are kept at a relatively low value (Figure 6). This indicates that there is a significant gain for the reserve configuration in longitudinal aggregation while the total cost is kept low. Thus, 0.25 was selected as the appropriate value of the CPF.

Under the scenario using the selected CPF, we obtained the following results of our planning: the selection frequency of each PU in the 100 runs and the best solution of the 100 runs (which had the minimum objective function value). In addition, such results were visualized using figures and compared to the existing wetland nature reserve network.

\section{Discussion of methods}

Imperfect but practical approaches of creating the fish distribution pattern

In this study, we collected spatial distribution information of the fish species through an extensive literature investigation, and gained presence/absence data of many species through SDMs and subsequent processing. Similar method has been applied in a large-scale research on amphibian conservation in China (Chen, 2013), and our study provides a specific approach to studies on fishes.

SDM is a reasonable approach to address data deficiency, which generalize the empirical relationships between the occurrences of species and the underlying habitat conditions to predict the probability of species occurrence or abundance within a given region (Guisan and Zimmermann, 2000). Environmental variables we used here are according to other SCPs for fishes (Esselman and Allan, 2011; Hermoso et al., 2011b; Moilanen et al., 2008). The outputs of our modelings demonstrated that these variables performed well, with the AUC values for $92.8 \%$ modelings higher than 0.75 .

Since biases usually exist in sample datasets, the outputs of the SDMs should be interpreted conservatively (Esselman and Allan, 2011). In our study, the high threshold of AUC (0.75) ensured that only species with well-performing modeling could be considered. Moreover, for any species,

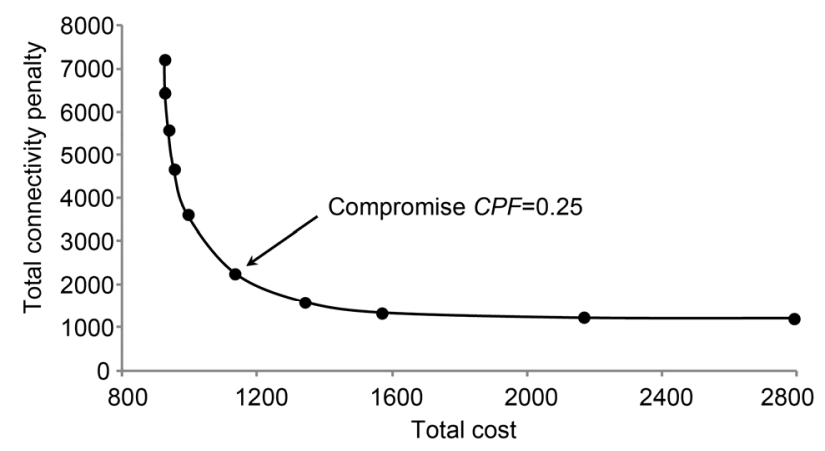

Figure 6 Trade-offs between the total connectivity penalty and the total cost (which are both mean values of 100 solutions) for different values of the connectivity penalty factor (CPF). When the CPF equals 0.25 , both the total connectivity penalty and the total cost were kept at a relatively low value. 
$80 \%$ of its training points with the highest probability of species occurrence were selected and the minimum probability value of these training points was used as the presence/absence threshold. Though it was subjective, it made sure that the predicted PDUs (and accepted presence PUs) of each species had a high probability of species occurrence.

We identified the distribution ranges of fish species based on the PDW and PDEDU both of which are delineated based on hydrological boundaries. In practice, it is more "objective" to predict species distribution ranges directly through SDM by using geographical variables, such as $x$ and $y$ coordinates, as environmental variables. However, the dispersion of freshwater fish and some other aquatics are strictly limited by hydrological barriers. Though many of them exhibit inter-watershed distribution caused by physiographic changes of land or occasional anastomosing of river systems during flood seasons throughout history (Loxterman and Keeley, 2012; Miller, 1966), they cannot naturally disperse across current hydrological barriers. Thus, it might be more appropriate to delineate distribution ranges of these taxa according to hydrological boundaries rather than predict them by using geographical variables in SDM.

Nevertheless, there are still some uncertainties lying in our approach determining the distribution range of fish species. First, the identified distribution ranges of fishes are strictly dependent on the distribution of sample sites. For any fish species, once a new sample site is found outside its previously delineated PDW or PDEDU, its distribution range should be readjusted. Second, the distribution of some fish species across hydrological barriers might result from occasional river separation caused by physiographic changes in history rather than natural dispersion through watercourses, so their populations on different sides of hydrological barriers (such as mountain ranges) are probably isolated. That means the concept of PDW might be unsuited for these species.

In addition, species sample data used here are derived from a comprehensive literature survey with publish dates spanning over four decades (1970-2013). During this period, the wetlands in MLYRB had experienced severe disturbances (Chen et al., 1997; Dudgeon, 2010; Huang and Chen, 2010; Yang et al., 2007). Under those disturbances, some freshwater fishes might become locally extinct because of habitat destruction. In our study, since the species sample data may include samples recorded temporally before such extensive disturbances, the data and the results of SDM may not reflect the current distribution patterns of species under disturbances. For any species, if the PUs where it has become locally extinct is still treated as PUs present in SCP, we might actually fail to meet its representation targets with the solution (Hermoso et al., 2011a). Thus, the results of our planning still have some uncertainties as regard to representativeness.

Furthermore, though referring to former studies, rationality of applying default parameters of Maxent and using PCA to reduce the variables in SDMs is still to be further studied.
Negotiable but appropriate setting of parameters in Marxan

Marxan is a powerful program for the design of the reserve network, which enables us to consider multiple factors in freshwater SCPs to achieve representativeness, persistence, and efficiency. In our study, on the basis of meeting the representation targets of fish species, cost, habitat condition, connectivity, and existing wetland nature reserves were all considered, which provided necessary information for taking into account persistence and efficiency. However, it should be noted that the results of planning would be sensitive to input data and parameter settings. Changes to input data or parameters would lead to different results. Consequently, though we tried our best to collect and use comprehensive input data and set appropriate parameters, uncertainties in the results would still occur due to data or information updates.

In many studies, the representation targets of protection objects were set as 10\%, 12\%, 15\% or above (Margules and Sarkar, 2007), however, Soulé and Sanjayan (1998) believed that the protection target of $10 \%$ or $12 \%$ was far from enough for many species. Therefore, we set relatively high representation targets for fishes in this planning so as to ensure adequacy for fish conservation. We set even higher representation targets for fishes with higher protection urgency and all fishes endemic to the MLYRB. To a certain extent, our methods took into account the different conservation needs among species. However, in terms of representativeness and persistence (Margules and Sarkar, 2007; Margules and Pressey, 2000), setting appropriate targets for all the fish species is dependent on an in-depth understanding of species' conservation needs, which relies on species-specific research. Thus, setting more reasonable representation targets still requires more theoretical support.

We did not use the economic cost of land as cost in Marxan because these costs are difficult to evaluate especially in the social background of China (Zhang et al., 2010). Instead, DI was used as the surrogate of cost to make PUs with fewer human disturbances more preferred in site selection, which led to a reserve network with better natural conditions. From another perspective, however, the total cost of the PUs in our planning could also reflect economic cost. First, the total cost equaled to the sum of $D I$ of all PUs. Thus, it could reflect the cumulative number of the PUs to some extent, which represented the total costs of wetland acquisition. Second, DI could also reflect economic factors. The reason is that the more serious the disturbances are, the higher cost the management and rehabilitation would be to reduce or eliminate such disturbances.

In the calculation of $D I$, the nine surrogates of human disturbances used (Table 3) might represent the main sources of human disturbance on freshwater wetland in the MLYRB. However, some other sources of disturbance in this region have impacted the fishes, such as overfishing and invasion of alien species (Cao, 2009; Huang and Chen, 2010; Wang et al., 2004; Yang et al., 2007). Moreover, we did not involve the accumulation of disturbances through 
drainage direction (Esselman and Allan, 2011) and the impact of climate changes on freshwater ecosystems (Huang and Chen, 2012a). In future planning, these issues should be taken into account.

For freshwater SCP, longitudinal connectivity is an important issue to concern and also a specific challenge which distinguishes freshwater SCP from terrestrial SCP (Pringle, 2001). With the Marxan platform, we adopted the approach introduced by (Hermoso et al., 2012, 2011b) to avoid the selection of isolated PUs and force the inclusion of PUs that are hydrologically closer. By doing so, selected PUs in solutions tended to be hydrologically connected or clustered, which offered "larger single reserves" for fishes. Nevertheless, we ignored the effects of vertical connectivity. The exchanges of surface water and ground water, which is regarded as vertical connectivity, would affect the fishes' habitat by changing the depth and area of the water body. Therefore, it is more reasonable to consider this connectivity further.

In the process of site selection, we locked existing fish reserves in the solution. It was a routine step in SCP to save cost. We further include non-fish wetland nature reserves in the initial reserve system before running Marxan, thus giving selection priority to these nature reserves relative to other areas. Although those nature reserves are not specialized in fish protection, adding the function of fish protection to existing wetland nature reserves is a method of less cost and higher feasibility compared to transforming land and water in other status into reserves.

Compliance and ethics The author(s) declare that they have no conflict of interest.

Acknowledgements We thank Guodong Zhang for providing guidance on the use of ArcGIS, and thank Environmental and Ecological Science Data Center for West China for environmental data. This work was supported by fund of State Forestry Administration of China-United Nations Development Program/ Global Environment Facility (83911 NP-2014007).

Abell, R., Allan, J.D., and Lehner, B. (2007). Unlocking the potential of protected areas for freshwaters. Biological Conservation 134, 48-63.

Anonymous (2005). Inland ports of China (in Chinese). Water Transportation Digest 69-70.

Austin, M., and Margules, C. (1986). Assessing representativeness. In Wildlife Conservation Evaluation, M. Usher, ed. (London, Chapman and Hall), pp. 45-67.

Ball, I.R., Possingham, H.P., and Watts, M. (2009). Marxan and relatives: software for spatial conservation prioritisation. In Spatial conservation prioritisation: quantitative methods and computational tools, A. Moilanen, K.A. Wilson, and H.P. Possingham, eds. (Oxford, Oxford University Press), pp. 185-195.

Bennett, A.F. (1998). Linkages in the landscape: the role of corridors and connectivity in wildlife conservation (Gland, International Union for Conservation of Nature).

Cao, W. (2009). If the Yangtze River can have a rest: Fish conservation in Yangtze River (in Chinese). China Three Gorges Construction, $148-157$

Changjiang Hydrological Committee of Hydrology Ministry (1999). Atlas of the Yangtze River Basin (in Chinese) (Beijing, China Map Press).

Chen, J., and Huang, X. (2010). Review of construction of wetland nature reserves in China. Paper presented at: Wetland Ecosystem Nature Reserve Management Seminar (in Chinese) (Nanchang, Nanchang University).

Chen, J., Li, B., and Wu, Q. (1997). Biodiversity of the Yangtze River basin and the strategy advances its coordinated development with economy (in Chinese). Biodiversity Science 5, 217-219.

Chen, Y. (1998). Fauna Sinica-Osteichthyes-Cypriniformes II (in Chinese) (Beijing, Science Press).

Chen, Y. (2013). Habitat suitability modeling of amphibian species in southern and central China: environmental correlates and potential richness mapping. Sci China Life Sci 56, 476-484.

Chu, X., Zheng, B., and Dai, D. (1999). Fauna Sinica-Siluriformes (in Chinese) (Beijing, Science Press).

Cowling, R., and Pressey, R. (2003). Introduction to systematic conservation planning in the Cape Floristic Region. Biol Conserv 112, 1-13.

Ding, C., and Li, F. (2006). Conservation and reserch of crested Ibis (in Chinese). Chin J Zool 40, 54-62.

Dudgeon, D. (2010). Requiem for a river: extinctions, climate change and the last of the Yangtze. Aquat Conserv 20, 127-131.

East China Sea Fisheries Research Institute of Chinese Academy of Fishery Sciences (1990). The Fishes of Shanghai (in Chinese) (Shanghai, Shanghai Scientific \& Technical Press).

ESRI (2012). ArcGIS 10.1 (Redlands, Environmental Systems Research Institute).

Esselman, P.C., and Allan, J.D. (2011). Application of species distribution models and conservation planning software to the design of a reserve network for the riverine fishes of northeastern Mesoamerica. Freshwater Biol 56, 71-88.

FAO/IIASA/ISRIC/ISSCAS/JRC (2009). Harmonized World Soil Database (version 1.1) (Rome, Food and Agriculture Organization and Laxenburg, International Institute For Applied Systems Analysis).

Fu, C., Wu, J, Chen, J., Qu, Q., and Lei, G. (2003). Freshwater fish biodiversity in the Yangtze River basin of China: patterns, threats and conservation. Biodivers Conserv 12, 1649-1685.

Game, E., and Grantham, H. (2008). Marxan user manual: for Marxan version 1.8. 10 (Vancouver, University of Queensland ).

Guisan, A., and Zimmermann, N.E. (2000). Predictive habitat distribution models in ecology. Ecol Model 135, 147-186.

Heiner, M., Higgins, J., Li, X., and Baker, B. (2011). Identifying freshwater conservation priorities in the Upper Yangtze River Basin. Freshwater Biol 56, 89-105.

Hermoso, V., Januchowski-Hartley, S., Linke, S., and Possingham, H.P. (2011a). Reference vs. present-day condition: early planning decisions influence the achievement of conservation objectives. Aquat Conser 21, 500-509.

Hermoso, V., Kennard, M.J., and Linke, S. (2012). Integrating multidirectional connectivity requirements in systematic conservation planning for freshwater systems. Divers Distrib 18, 448-458.

Hermoso, V., Linke, S., Prenda, J., and Possingham, H.P. (2011b). Addressing longitudinal connectivity in the systematic conservation planning of fresh waters. Freshwater Biol 56, 57-70.

Higgins, J.V., Bryer, M.T., Khoury, M.L., and Fitzhugh, T.W. (2005). A freshwater classification approach for biodiversity conservation planning. Conserv Biol 19, 432-445.

Hijmans, R.J., Cameron, S.E., Parra, J.L., Jones, P.G., and Jarvis, A. (2005). Very high resolution interpolated climate surfaces for global land areas. Int J Climatol 25, 1965-1978.

Huang, X., and Chen, J. (2010). Review and prospect of development of wetland nature reserves in Middle and Lower Yangtze River Basin. In Analysis of Top Ten Cases About Effective Management of Wetland Nature Reserves in Middle and Lower Yangtze River Basin (in Chinese), J. Chen, G. Lei, and X. Wang, eds. (Shanghai, Fudan Press), pp. $1-17$.

Huang, X., and Chen, J. (2012a). Extreme climate change and wetlands in middle and lower reaches of Yangtze River Basin (in Chinese). Kexue 64, 35-37.

Huang, X., and Chen, J. (2012b). Problems facing wetland nature reserves in China in the new era and recommendations for overcoming them (in 
Chinese). Biodiv Sci 20, 774-778.

Hunan Fisheries Science Institute (1980). The Fishes of Hunan (in Chinese) (Changsha, Hunan Scientific \& Technical Press).

Jiang, N. (2002). Lake Database in China (in Chinese) (Nanjing Institute of Geography \& Limnology, Chinese Academy of Sciences).

Kirkpatrick, J.B. (1983). An iterative method for establishing priorities for the selection of nature reserves-an example from Tasmania. Biol Conserv 25, 127-134.

Laboratory of fish of Hubei Hydrobiology Institute (1976). The Fishes of the Yangtze River (in Chinese) (Beijing, Science Press).

Lehner, B., Liermann, C.R., Revenga, C., Voeroesmarty, C., Fekete, B. Crouzet, P., Doell, P., Endejan, M., Frenken, K., Magome, J., Nilsson, C., Robertson, J.C., Roedel, R., Sindorf, N., and Wisser, D. (2011). High-resolution mapping of the world's reservoirs and dams for sustainable river-flow management. Front Ecol Environ 9, 494-502.

Linke, S., Norris, R., and Pressey, R. (2008). Irreplaceability of river networks: towards catchment-based conservation planning. J Appl Ecol 45, 1486-1495

Linke, S., Turak, E., and Nel, J. (2011). Freshwater conservation planning: the case for systematic approaches. Freshwater Biol 56, 6-20.

Liu, J., Ouyang, Z., Pimm, S.L., Raven, P.H., Wang, X., Miao, H., and Han, N. (2003). Protecting China's biodiversity. Science 300, $1240-1241$.

Loxterman, J.L., and Keeley, E.R. (2012). Watershed boundaries and geographic isolation: patterns of diversification in cutthroat trout from western North America. BMC Evol Biol 12, 38.

Maidment, D.R. (2002). Arc Hydro: GIS for Water Resources (Redlands, ESRI Press).

Mao, J., and Xu, S. (1991). Fauna of Zhejiang-Fresh Water Fishes (in Chinese) (Hangzhou, Zhejiang Scientific \& Technical Press).

Margules, C., and Sarkar, S. (2007). Systematic Conservation Planning (New York, Cambridge University Press).

Margules, C.R., and Pressey, R.L. (2000). Systematic conservation planning. Nature 405, 243-253.

Miller, R.R. (1966). Geographical distribution of central American freshwater fishes. Copeia, 773-802.

Ministry of Water Resource of the People's Republic of China (2001). Code for China Water Gate Name (in Chinese) (Beijing, China WaterPower Press).

Moilanen, A., Leathwick, J., and Elith, J. (2008). A method for spatial freshwater conservation prioritization. Freshwater Biol 53, 577-592.

$\mathrm{Ni}$, Y., and Wu, H. (2006). The Fishes of Jiangsu (in Chinese) (Beijing, China Agriculture Press).

Phillips, S.J., Anderson, R.P., and Schapire, R.E. (2006). Maximum entropy modeling of species geographic distributions. Ecol Model 190, 231-259.

Phillips, S.J., Dudík, M., and Schapire, R.E. (2004). A maximum entropy approach to species distribution modeling. Paper presented at: Proceedings of the twenty-first international conference on Machine learning (Banff, Alberta, Canada, ACM Press).

Possingham, H., Wilson, K., Andelman, S., and Vynne, C. (2006). Protected areas: goals, limitations, and design. In Principles of Conservation Biology, M.J. Groom, G.K. Meefe, and C.R. Carroll, eds. (Sunderland, Sinauer Associates, Inc.), pp. 509-533.

Pressey, R.L., Watts, M.E., Barrett, T.W., and Ridges, M.J. (2009). The C-Plan conservation planning system: origins, applications, and possible futures. In Spatial Conservation Prioritization: Quantitative Methods and Computational Tools, A. Moilanen, K.A. Wilson, H.P.
Possingham, eds. (Oxford, Oxford University Press), pp. 211-234.

Pringle, C.M. (2001). Hydrologic connectivity and the management of biological reserves: a global perspective. Ecol Appl 11, 981-998.

Ran, Y., Li, X., and Lu, L. (2010). Land Cover Products of China (in Chinese) (Lanzhou, Cold and Arid Regions Science Data Center).

Rondinini, C., and Pressey, R.L. (2007). Special section: systematic conservation planning in the European landscape: conflicts, environmental changes, and the challenge of countdown 2010. Conserv Biol 21, 1404-1405.

Sarkar, S., Pressey, R.L., Faith, D.P., Margules, C.R., Fuller, T., Stoms, D.M., Moffett, A., Wilson, K.A., Williams, K.J., Williams, P.H., and Andelman, S. (2006). Biodiversity conservation planning tools: Present status and challenges for the future. Annu Rev Env Resour 31, 123-159.

Shao, M. (2004). Anhui wild Chinese alligator Resources and Protection measures (in Chinese). Anhui Forest Sci Technol, 43-44.

Smith, R.J., Goodman, P.S., and Matthews, W.S. (2006). Systematic conservation planning: a review of perceived limitations and an illustration of the benefits, using a case study from Maputaland, South Africa. Oryx 40, 400-410.

Soulé, M.E. (1987). Viable Populations for Conservation (Cambridge, Cambridge University Press).

Soulé, M.E., and Sanjayan, M. (1998). ECOLOGY: Conservation Targets: Do They Help? Science 279, 2060-2061.

Vanewright, R.I., Humphries, C.J., and Williams, P.H. (1991). What to protect-systematics and the agony of choice. Biol Conserv 55, 235-254.

Wang, H., Yao, T., Wang, C., and Yu, X. (2004). Threat and pressure for the biodiversity conservation in the area along the middle reaches of changjiang river with suggestions on the countermeasure (in Chinese). Resour Environ Yangtze Basin 13, 429-433.

Wang, R., Shao, M., Wang, C., and Zhu, J. (2010). Habitat management and population recovery - case of effective management of Chinese Alligator nature reserve. In Analysis of Top Ten Cases About Effective Management of Wetland Nature Reserves in Middle and Lower Reaches of Yangtze River Basin (in Chinese), J. Chen, G. Lei, and X. Wang, eds. (Shanghai, Fudan Press), pp. 52-71.

Wen, F., and Li, E. (2010). Scientific research and practice of rehabilitation of wetland vegetation - case of effective management of Hubei Honghu wetland nature reserve. In Analysis of Top Ten Cases About Effective Management of Wetland Nature Reserves in Middle and Lower Reaches of Yangtze River Basin (in Chinese), J. Chen, G. Lei, and X. Wang, eds. (Shanghai, Fudan Press), pp. 172-190.

Yang, G. (1988). The Fishes of Hubei (in Chinese) (Wuhan, Hubei Scientific \& Technical Press).

Yang, G., Weng, L., and Li, L. (2007). Yangtze Conservation and Development Report 2007 (in Chinese) (Wuhan, Yangtze Press).

Yue P. (2000). Fauna Sinica-Osteichthyes-Cypriniformes III (in Chinese) (Beijing, Science Press).

Zhang, L., Ouyang, Z., and Xu, W. (2015). Theory, work frame and hot issues of systematic conservation planning (in Chinese). Acta Ecol Sin $35,1284-1295$.

Zhang, L., Ouyang, Z., Xu, W., Li, Z., and Zhu, C. (2010). Biodiversity priority areas analysis for amphibians and reptiles in the yangtze basin based on systematic conservation planning idea (in Chinese). Resour Environ Yangtze Basin 19, 1020-1028.

Zhang, S.Y. (2001). Fauna Sinica-Acipenseriformes Elopiformes Clupeiformes Gonorhynchiformes (in Chinese) (Beijing, Science Press).

Open Access This article is distributed under the terms of the Creative Commons Attribution License which permits any use, distribution, and reproduction in any medium, provided the original author(s) and source are credited.

\section{Supporting Information}

\section{Table S1 List of fish species}

The supporting information is available online at life.scichina.com and link.springer.com. The supporting materials are published as submitted, without typesetting or editing. The responsibility for scientific accuracy and content remains entirely with the authors. 